\title{
Myositis ossificans mimicking sarcoma: a not so rare bioptic diagnostic pitfall
}

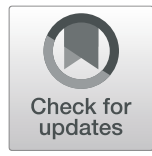

Luisa Cortellazzo Wiel ${ }^{1 \dagger}$, Matteo Trevisan ${ }^{1 * \dagger}$ (D) Flora Maria Murru², Marco Rabusin² and Egidio Barbi ${ }^{1,2}$

\begin{abstract}
Background: Myositis ossificans (MO) is a heterotopic bone formation in soft tissues, usually caused by traumas or neuropathies. Although the aetiology remains unclear, $\mathrm{MO}$ is supposed to be an osteoblast metaplasia with a benign and self-limiting course. Remarkably, at onset MO can be clinically, radiologically and histologically indistinguishable to soft tissue malignancies, especially in cases lacking a history of trauma, leading to misdiagnoses and improper treatments.

Case presentation: A 13-year-old male was referred to the Oncology Department because of a previous diagnosis of osteogenic sarcoma of his left thigh. The diagnosis was made upon a history of isolated thigh pain in the absence of traumas, the evidence of a contrast-enhanced soft tissue mass on magnetic resonance imaging and the histological findings of atypical nuclei and mitotic figures. The lesion was eventually radiologically unchanged after five cycles of chemotherapy; thus, the child was referred for radical surgery. At admission, endorsing the child wellappearance, together with the evidence of a reduced calcified lesion on a further magnetic resonance, a clinical suspicion of myositis ossificans was raised. Hence, the excisional biopsy confirmed the pathognomonic zonal pattern of myositis ossificans.

Conclusions: This case highlights some frequent diagnostic pitfalls facing myositis ossificans. A lacking history of traumas, along with a too early radiological and histological evaluation can lead to a misdiagnosis of soft tissue malignancies. Even in the absence of a clear history of trauma, a painful soft tissue swelling with a benign clinical course should raise the suspicion of myositis ossificans.
\end{abstract}

Keywords: Myositis ossificans, Heterotopic calcification, Osteogenic sarcoma, Zonal pattern organisation, Case report

\section{Background}

Myositis ossificans (MO) consists of the formation of lamellar bone in the context of soft tissues, especially large skeletal muscles of arms and thighs $[1,2]$. Two different forms of acquired $\mathrm{MO}$ can be recognized: neurogenic and non-neurogenic; the latter can be divided, in turn, into post-traumatic circumscribed MO $(60-75 \%$

\footnotetext{
* Correspondence: matteo.trevisan91@gmail.com

${ }^{\dagger}$ Luisa Cortellazzo Wiel and Matteo Trevisan contributed equally as co-first authors

${ }^{1}$ Department of Medicine, Surgery, and Health Sciences, University of Trieste, Piazzale Europa 1, 34127 Trieste, Italy

Full list of author information is available at the end of the article
}

of cases) [3] and idiopathic/pseudomalignant. Posttraumatic MO can result from both severe direct injuries and recurrent minor trauma, even in the form of abuse [4].

While pathogenesis is still not completely understood, the current hypothesis is that of an endothelialmesenchymal transition, in which mesenchymal stem cells differentiate into chondrocytes and osteoblasts guided by a cytokine cascade following trauma, ischemia or inflammation [5].

The natural history of MO consists of a rapid overgrowth in the first 4 weeks, when osteoblasts and chondrocytes produce new osteoid matrix in the middle of 
the lesion. The typical peripheral calcifications are detectable between the fourth and tenth week when the lesion stops growing. Once the lesion is mature, the socalled "zonal pattern organization" can be radiologically and histologically appreciated, consisting on a central area of proliferating fibroblasts with possible necrosis and haemorrhage, followed by an intermediate zone of immature osteoid tissue along with cartilage, resulting from enchondral ossification and an outer shell of lamellar mature bone $[6,7]$.

The clinical presentation consists of painful swelling of the involved site with reduced range of motion of the adjacent joint [8]. A pointed anamnesis allows a prompt diagnosis in the majority of cases. Nevertheless, in the presence of a growing mass without any history of trauma, the suspicion of a bone or soft tissue cancer has to be raised. Even though radiological imaging can help identify the centripetal calcifications of the lesion, sparing the cortical bone, in the first weeks these features can lack. The biopsy is deserved to indeterminate lesions, but if performed too early or within the core lesion, the presence of pleomorphic osteoblasts with atypical nuclei and mitosis can be misleading. Hence, in the first weeks, MO can be almost indistinguishable from cancers [9]. A case of myositis ossificans through the common diagnostic pitfalls is reported.

\section{Case presentation}

A 13-year-old male was referred from another hospital to the Oncology Department after receiving a diagnosis of osteogenic sarcoma of his left thigh. Seven months before, he had started to complain about an isolated pain on his left thigh, in the absence of limp, fever or any history of trauma. After an unremarkable X-ray, he underwent a magnetic resonance imaging (MRI) of the left leg, showing a well-demarcated soft tissue mass of $5 \times 4 \times 3$ $\mathrm{cm}$ within the proximal third of the left quadriceps, sparing the cortical bone (Fig. 1). The lesion enhanced homogenously by contrast and was surrounded by widespread oedema of the entire vastus lateralis and intermedius. A biopsy showed several large polygonal to spindle cells with atypical nuclei, mitotic figures and extensive necrosis, along with foci of abnormal osteoid formation, chondroid elements and calcifications. A diagnosis of osteogenic sarcoma was made. After five cycles of chemotherapy with methotrexate, adriamycin and cisplatin, the radiological findings were unchanged. The patient was therefore referred for surgery and further chemotherapy as needed. At admission, the clinical examination was unremarkable. An MRI confirmed the presence of a residual calcified muscle lesion of $4.2 \times$ $1.2 \times 0.7 \mathrm{~cm}$. Endorsing the benign course of the disease, the clinical suspicion of myositis ossificans was raised. Hence, he underwent a sparing limb surgery. The

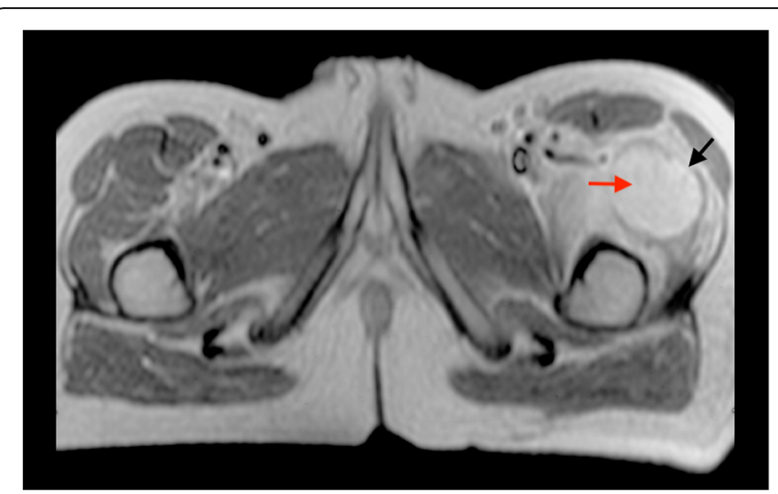

Fig. 1 Contrast T1-weighted axial MRI: Well-defined contrastenhanced lesion $(5 \times 4 \times 3 \mathrm{~cm})$ within the proximal third of the left vastus lateralis (red arrow) sparing the cortical bone and separated from surrounding oedema by a hypointense rim (black arrow)

histological sample showed the presence of three circumferential zones: islets of mature osteoblasts and fibroblasts without mitotic or atypical nuclei in the middle of the striated muscle, an interim zone with spindle cells surrounded by an osteoid stroma and a peripheral area with well-organized lamellar bones, confirming the diagnosis of myositis ossificans (Fig. 2). Neoplastic markers tested negative. The patient was discharged with the recommendation of muscular rehabilitation.

\section{Discussion}

Even if MO generally displays the typical radiological and histological features in the course of the disease, it can represent a diagnostic challenge during the first weeks from onset, requiring a differential diagnosis with malignancy.

Plain radiographs typically show a lesion made up of a central radiolucent area indicating immature bone formation with a calcified peripheral rim of mature ossification. A thin radiolucent cleft separates the ossified mass from the adjacent cortex, which is intact, thus guiding the differential diagnosis with bone malignancies [10]. However, soft tissue calcifications are usually detectable not earlier than 4 weeks after the onset of the disease [11] and the lesion usually reaches its typical appearance after 6 months. Before this interval, MO can be radiologically indistinguishable to extraskeletal osteosarcomas. MRI allows an earlier recognition of the lesion: during the acute phase of the disease, it shows the presence of heterogeneous signal intensity on T1-weighted sequences without contrast enhancement, representative of blood products. These lesions will eventually progress to a pattern of lamellar bone with low signal intensity on all sequences [12]. To confirm MRI findings, the performance of computed tomography (CT) is recommended to recognise the characteristic centripetal calcifications [13] before they become detectable by 


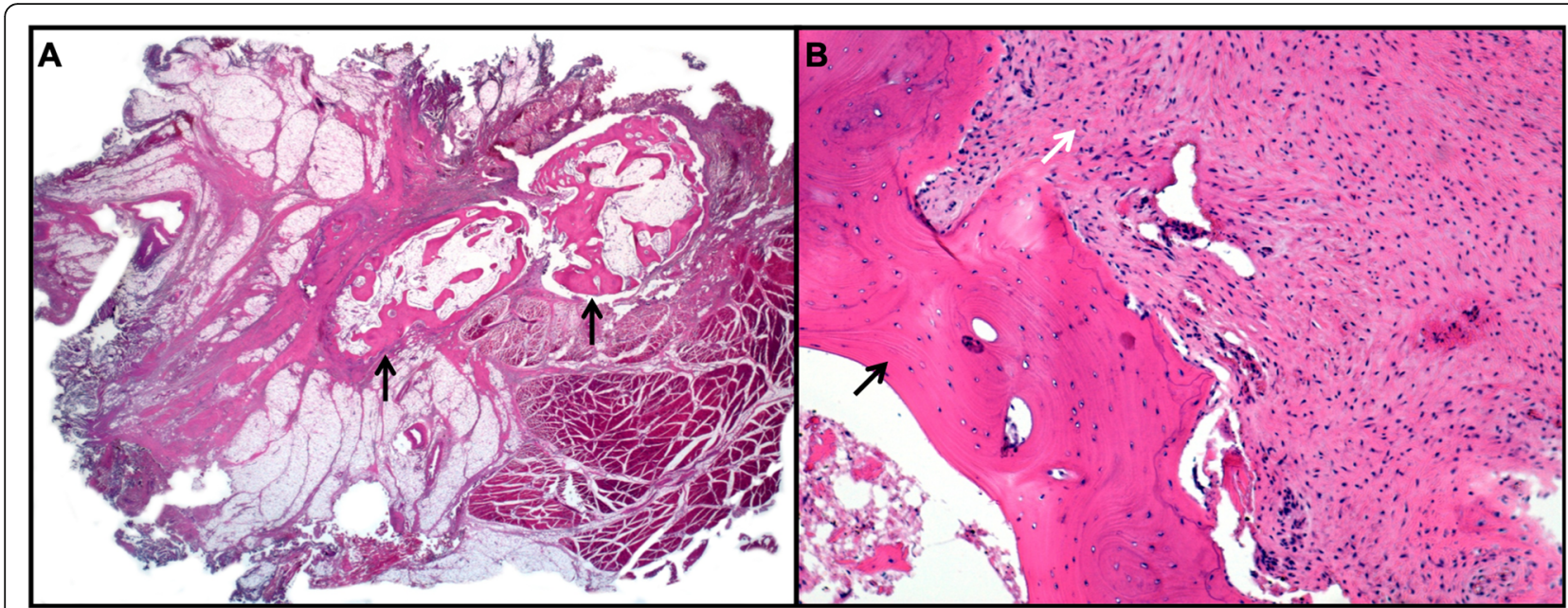

Fig. 2 Histological sample from the thigh lesion. Panel a: hematoxylin and eosin (2X), mature lamellar bone within a stroma of adipo-muscular and striated muscular tissue. Panel $\mathbf{b}$ : hematoxylin and eosin (20X), absence of atypical mitosis or cellular pleomorphism within both bone (black arrow) and stromal tissue (white arrow)

standard radiography [14]. The main differential diagnoses of MO are soft tissue abscess and sarcoma: the latter typically displays contrast enhancement and generally lacks the peripheral calcified rim of $\mathrm{MO}$ [15].

Biopsy is deserved to indeterminate lesions. Remarkably through the sole performance of a fine needle aspiration cytology, as well as if the biopsy sample is taken from the lesion core or is performed too early, it is likely to run into the misdiagnosis of soft tissue sarcoma, due to the presence of isolated mitotic fibroblast-like cells [16].

Table 1 summarizes the main clinical, radiological and histological differences between $\mathrm{MO}$ and osteogenic sarcomas.

In this case, at the onset of disease, the absence of calcifications on radiological imaging and the finding of mitotic and atypical cells on the first biopsy led to a misdiagnosis of osteogenic sarcoma and the corresponding chemotherapy. However, the first MRI already exhibited some atypical features for osteosarcoma, consisting in the sharp demarcation of the soft-tissue mass, the presence of a circumscribing hypointense rim and oedema and the sparing of the cortical bone (Table 1). At referral, the repeated MRI showed a lesion not reduced in size after chemotherapy, without contrast-enhancement and with new calcifications. Finally, the excisional biopsy demonstrated the so-called "zonal pattern organization" allowing the diagnosis of MO.

Myositis ossificans is a benign self-limiting condition, and the treatment of choice is conservative. After an initial period of rest, gradual remobilization is recommended. Surgery is deserved to persistently symptomatic cases [17] and is preferably delayed until the complete maturation of the lesion has been reached, and ossification has stopped to prevent the occurrence of relapses $[18,19]$.

\section{Conclusion}

This case highlights the diagnostic pitfalls of myositis ossificans. Chronic and aspecific symptoms without any

Table 1 Main differences between myositis ossificans and osteogenic sarcoma

\begin{tabular}{lll}
\hline & MYOSITIS OSSIFICANS & OSTEOGENIC SARCOMA \\
\hline CLINICAL & Rapidly-growing, painful swelling and joint stiffness; & Local pain, swelling and limp; \\
& History of trauma. & Night-time awakenings with bony pain; \\
& & Pathological fractures;
\end{tabular}

RADIOLOGICAL Rx/CT: calcified peripherical rim with a radiolucent cleft between the lesion and the cortical bone.

$\mathbf{R x} / \mathbf{C T}$ : Periosteal reaction, Codman's triangle, sunburst sign;

MRI: early T2-weighted hyperintensity (oedema) and later hypoinlobulated mass (cauliflower-like).

tense rim in all sequences;

Usually no contrast-enhancement.

HISTOLOGICAL "Zonal pattern organization":

1. Peripherical mature lamellar bone;

2. Middle zone: immature osteoid matrix;

3. Inner zone: proliferating fibroblast tissue.

MRI: heterogeneous or solid contrast-enhancement.

Spindle/polygonal, malignant mesenchymal cells; hemorrhagic and necrotic lesions;

MDM2 and CDK4 +. 
history of trauma, together with a precocious radiological and histological evaluations can be misleading. When history, symptoms and imaging are not diagnostic, an excisional biopsy is recommended.

MO should be considered in the differential diagnosis of bone and soft tissue sarcomas in front of painful soft tissue swelling, valuing the radiological pattern and the benign course of the disease, even in the absence of a clear history of trauma, to avoid unnecessary treatments and to maximize functional outcomes.

\section{Abbreviations \\ MO: Myositis Ossificans; MRI: Magnetic Resonance Imaging; CT: Computed Tomography}

\section{Acknowledgements}

We thank the patient and his parents for their high availability, allowing us to publish this case report.

\section{Authors' contributions}

All authors listed on the manuscript have seen and approved the submission of this version of the manuscript, taking full responsibility for the manuscript. Luisa Cortellazzo Wiel and Matteo Trevisan wrote the first draft of the manuscript. Luisa Cortellazzo Wiel, Matteo Trevisan and Marco Rabusin followed the patient clinically. Flora Maria Murru performed radiological imaging. Marco Rabusin and Egidio Barbi revised the manuscript and made substantial scientific contributions.

\section{Funding}

None of the authors received any honorarium, grant, or other forms of payment for this study.

\section{Availability of data and materials}

No supporting data are available.

\section{Ethics approval and consent to participate}

Not applicable.

\section{Consent for publication}

The authors declare having obtained the written consent from the patient's parents for publication of the photographs in all forms and media.

\section{Competing interests}

The authors declare that they have no competing interests.

\section{Author details}

'Department of Medicine, Surgery, and Health Sciences, University of Trieste, Piazzale Europa 1, 34127 Trieste, Italy. ${ }^{2}$ Institute for Maternal and Child Health, IRCCS "Burlo Garofolo", Trieste, Italy.

Received: 2 December 2019 Accepted: 24 July 2020

Published online: 31 July 2020

\section{References}

1. Gindele A, Scwamborn D, Tsironis K, Benz-Bohm G. Myositis ossificans traumatica in young children: report of three cases and review of literature. Pediatr Radiol. 2000;30:451-9.

2. Nishio J, Nabeshima K, Iwasaki H, Naito M. Non-traumatic myositis ossificans mimicking a malignant neoplasm in an 83-year-old woman: a case report. J Med Case Rep. 2010;4:270.

3. Rosenberg AE. Myositis ossificans and fibroosseous pseudotumor of digits. In: CDM F, Unni KK, Mertens F, editors. Pathology and genetics of tumors of soft tissue and bone. Lyon: International Agency for Research on Cancer (IARC); 2002. p. 52-4.

4. Harmon J, Rabe AJ, Nichol KK, Shiels WE. Precervical myositis ossificans in an infant secondary to child abuse. Pediatr Radiol. 2012;42:881-5.

5. Medici D, Olsen BR. The role of endothelial-mesenchymal transition in heterotopic ossification. J Bone Miner Res. 2012;27(8):1619-22.
6. Folpe AL, Gown AM. Cartilaginous and osseous soft tissue tumors. In: Goldblum JR, Folpe AL, Weiss WS, editors. Enzinger \& Weiss's soft tissue tumors, ed 6. Philadelphia: Elsevier; 2014. p. 917-46.

7. Stavride E, Bintoudi A, Zagalioti SC, Galanis N. Myositis ossificans in the infraspinatus muscle: the key to diagnosis. Clin Case Rep. 2019;7(11):2260-2.

8. Garland DE. A clinical perspective on common forms of acquired heterotopic ossification. Clin Orthop Relat Res. 1991;263:13-29.

9. Say F, Coşkun S, Bülbül M, Alici Ö. Myositis ossificans on the forearm in a 10-year-old girl. J Pediatr Orthop B. 2015;24(3):223-5.

10. Parikh J, Hyare $H$, Saifuddin A. The imaging features of post-traumatic myositis ossificans, with emphasis on MRI. Clin Radiol. 2002;57(12):1058-66.

11. Thorndike A. Myositis ossificans traumatica. J Bone Joint Surg Am. 1940; 22(2):315-23.

12. Ogilvie-Harris DJ, Fornasier VL. Pseudomalignant myositis ossificans: heterotopic new-bone formation without a history of trauma. J Bone Joint Surg Am. 1980;62(8):1274-83.

13. Kransdorf MJ, Murphey MD. Radiologic evaluation of soft-tissue masses: a current perspective. AJR Am J Roentgenol. 2000;175(3):575-87.

14. Shehab D, Elgazzar AH, Collier BD. Heterotopic ossification. J Nucl Med. 2002;43(3):346-53.

15. Wilkerson BW, Crim JR, Hung M, Layfield L. Characterization of synovial sarcoma calcification. AJR Am J Roentgenol. 2012;199(6):W730-4.

16. Mokhtari M, Kumar PV, Rezazadeh S. Confusing cytological findings in myositis Ossificans. Acta Cytol. 2012;56:565-70.

17. Ellerin BE, Helfet D, Parikh S, et al. Current therapy in the management of heterotopic ossification of the elbow: a review with case studies. Am J Phys Med Rehabil. 1999;78(3):259-71.

18. Conner GA, Duffy M. Myositis ossificans: a case report of multiple recurrences following third molar extractions and review of the literature. J Oral Maxillofac Surg. 2009;67:920-6.

19. Walczak BE, Johnson CN, Howe BM. Myositis Ossificans. J Am Acad Orthop Surg. 2015;23:612-22.

\section{Publisher's Note}

Springer Nature remains neutral with regard to jurisdictional claims in published maps and institutional affiliations.

\section{Ready to submit your research? Choose BMC and benefit from:}

- fast, convenient online submission

- thorough peer review by experienced researchers in your field

- rapid publication on acceptance

- support for research data, including large and complex data types

- gold Open Access which fosters wider collaboration and increased citations

- maximum visibility for your research: over $100 \mathrm{M}$ website views per year

At BMC, research is always in progress.

Learn more biomedcentral.com/submissions 